\title{
Calibrations of Phase Abundance, Composition, and Particle Size Distribution for Olivine-Orthopyroxene Mixtures From Reflectance Spectra
}

\author{
Edward A. Cloutis ${ }^{1}$ \\ Planetary Geosciences Division, Hawaii Institute of Geophysics \\ University of Hawaii at Manoa, Honolulu \\ Michael J. Gaffey \\ Department of Geology, Rensselaer Polytechnic Institute, Troy, New York \\ TIMOTHY L. JACKOWSKI ${ }^{2}$ AND KEVIN L. REED ${ }^{3}$ \\ Planetary Geosciences Division, Hawaii Institute of Geophysics \\ University of Hawaii at Manoa, Honolulu
}

\begin{abstract}
Spectral reflectance measurements of characterized (phase abundance, particle size) mixtures of olivine and orthopyroxene were utilized to define the correlations between spectral and albedo parameters of such assemblages and their mineralogical or textural properties. Thirty-three different spectral parameters falling into three general classes (relative or ratioed, absolute or albedo, and wavelength) were investigated for empirical sensitivity to one or more of the mixture properties. Theoretical considerations and previous experimental observations were utilized to understand their functional relationships. The ratio of areas for the 1- and 2- $\mu \mathrm{m}$ absorption bands is shown to be a sensitive indicator of the olivineorthopyroxene abundance and is very nearly independent of particle size and mineral composition. In conjunction with an abundance determination, the wavelength position of the $1-\mu \mathrm{m}$ absorption feature can be utilized to determine the molar iron contents of the olivine and orthopyroxene phases. This calibration is insensitive to particle size but will produce systematic deviations if the phases have signifcantly different iron contents or if more than a few percent of a clinopyroxene component is present. The spectral albedo in the $0.6-$ to $0.7-\mu \mathrm{m}$ region is relatively insensitive to phase abundance and can be used to constrain particle size if phase composition has been determined.
\end{abstract}

\section{INTRODUCTION}

For the foreseeable future, remote sensing will be the only available means for deriving information about the surface properties of many solar system bodies. Reflectance spectroscopy is one of the most powerful tools in remote sensing for characterizing surface mineralogy, but all too often spectra are analyzed only in a qualitative sense. Increasingly sophisticated and quantitative interpretative techniques are required to keep pace with continuing improvements in the quality of reflectance spectra, whether they are obtained from laboratory samples, telescopes, or spacecraft.

In principle, it should be possible to fully deconvolve a reflectance spectrum to determine the basic properties of the assemblage such as abundance and composition of the endmember species and the physical properties of the mixture. At present, no viable theoretical models exist for accurately determining the properties of the mineral components contributing to the reflectance spectra of a mixture, although some work in "semiempirical" models shows considerable promise [Johnson et al., 1983, 1985]. Empirical calibration studies suffer from the fact that an impossibly large number of laboratory spectra

\footnotetext{
${ }^{1}$ Now at Department of Geology, University of Alberta, Edmonton, Alberta, Canada.

${ }^{2}$ Now at Concord, California.

${ }^{3}$ Now at Honolulu, Hawaii.

Copyright 1986 by the American Geophysical Union.
}

Paper number 5B5866.

$0148-0227 / 86 / 005 \mathrm{~B}-5866 \$ 05.00$ must be generated to account for all the possible mineral assemblages to be found throughout the solar system. This problem can be partially circumvented by focusing on a specific subset of cosmically important minerals and studying their behavior in detail.

In the present study, efforts have concentrated on deriving analytical techniques for deconvolving the reflectance spectra of olivine-pyroxene assemblages. These particular minerals were chosen because they are the most common anhydrous minerals formed from the condensation of a gas of solar composition [Lewis, 1973; Clayton, 1979]. Consequently, they are an important component of many bodies in the inner solar system. An improved understanding of their spectral behavior would provide the means of obtaining a better insight into the nature and evolution of such bodies from remote sensing studies.

A significant body of work exists on the spectral properties of olivine, pyroxene, and admixtures of the two, resulting in a number of important qualitative and quantitative observations. Olivine exhibits a broad asymmetric feature (three overlapping individual absorption features) near $1 \mu \mathrm{m}$, lowcalcium pyroxene (orthopyroxene) exhibits two well-defined absorption features near 1 and $2 \mu \mathrm{m}$ (bands I and II, respectively), and calcic pyroxenes (clinopyroxenes) exhibit more complex features near 1 and $2 \mu \mathrm{m}$. All of these absorption features arise from electronic transitions in $\mathrm{Fe}^{2+}$ cations located in specific crystallographic sites within the minerals. These absorption features exhibit systematic shifts in band minima positions toward longer wavelengths with increasing iron $\left(\mathrm{Fe}^{2+}\right)$ content and, in the case of the pyroxenes, with 
increasing calcium content [Burns, 1970a; Adams and McCord, 1972; Adams, 1974, 1975; Hazen et al., 1977, 1978].

The intensity of the absorption features (e.g., band depth, band area) increases in both mineral species with increases in iron content [Adams, 1975; Burns, 1970a, b; Hunt and Salisbury, 1970; Hazen et al., 1977, 1978]. The molar extinction coefficient of $\mathrm{Fe}^{2+}$ in the pyroxene structure is nearly an order of magnitude higher than in the olivine structure. Therefore in intimate mixtures of the two phases with subequal molar iron abundances, the pyroxene features continue to dominate the spectrum until pyroxene is only a minor component of the mixture.

A prominent absorption feature in the reflectance spectra of both the olivine and pyroxene occurs near $1 \mu \mathrm{m}$. In most olivines it manifests itself as a relative minimum with two side lobes. Burns [1970a] attributes the stronger central feature to $\mathrm{Fe}^{2+}$ located in the less centrosymmetric octahedral M2 crystallographic sites and the weaker sidelobes to $\mathrm{Fe}^{2+}$ in more centrosymmetric M1 sites. The $1-\mu \mathrm{m}$ absorption feature in the orthopyroxene spectrum is symmetric and is due to the presence of $\mathrm{Fe}^{2+}$ in the more distorted octahedral M2 crystallographic sites in pyroxenes [Bancroft et al., 1967; Burns, $1970 b]$, which produces large separation between the electronic energy levels of the absorbing cation and hence absorption features which are well separated and not overlapping. (The intensity of a crystal field absorption feature per unit of the absorbing species, typically a transition metal cation such as $\mathrm{Fe}^{2+}$, increases in crystallographic sites which are less centrosymmetric and in which the cation is displaced from the center of symmetry of the site.) Iron rich orthopyroxenes will also exhibit broadened bands and/or multiple minima in the $1-\mu \mathrm{m}$ spectral region, as the M2 crystallographic sites become full and iron enters the M1 site [Burns, 1970b].

The pyroxenes exhibit a prominent absorption band in the $2-\mu \mathrm{m}$ spectral region. There is no corresponding feature in the spectrum of olivine. The presence of the band in the orthopyroxene spectra is due to crystal field absorptions by $\mathrm{Fe}^{2+}$ in the highly distorted (M2) octahedral sites [Burns, 1970b; Burns et al., 1972].

The $1-\mu \mathrm{m}$ absorption features in the spectra of olivines and orthopyroxenes and the $2-\mu \mathrm{m}$ feature in orthopyroxenes shift toward longer wavelength with increasing molar iron content [Burns, 1970a, b; Adams, 1974, 1975; Hazen et al., 1977, 1978]. The shifts in the wavelength positions of both the $1-$ and $2-\mu \mathrm{m}$ band minima are due to the effects of substituting the larger $\mathrm{Fe}^{2+}$ cation into the crystallographic site of the smaller $\mathbf{M g}^{2+}$ cation, resulting in changes in the crystal structure and thus in the crystal fields and the electronic transitions which produce these absorption features.

The nature of the weak absorption feature found in all our spectra at about $0.65 \mu \mathrm{m}$ is subject to debate. In olivines this absorption has been variously attributed to a spin forbidden $\mathrm{Fe}^{2+}$ transition [Burns, 1970a; Runciman et al., 1973a; Hazen et al., 1977], to a spin forbidden $\mathrm{Fe}^{3+}$ transition [Burns et al., 1973], to an $\mathrm{Fe}^{3+}-\mathrm{Fe}^{2+}$ charge transfer [Mao and Bell, 1972], or possibly to a spin forbidden $\mathrm{Fe}^{2+}$ transition. In various pyroxenes a similar absorption feature in this spectral region has been attributed to an $\mathrm{Fe}^{2+}-\mathrm{Fe}^{3+}$ charge transfer transition [Burns, 1970b], to $\mathrm{Ti}^{3+}$ spin allowed transitions [Burns et al., 1972], to spin-forbidden $\mathrm{Fe}^{2+}$ transitions [Runciman et al., $1973 b$ ], and to a $\mathrm{Cr}^{3+}$ absorption [Rossman, 1977; Hazen et al., 1978]. It is probable that for the specific mineral samples studied, each of these assignments is at least partially correct, and there may be no method of uniquely assigning these features to specific cations.

The steep drop-off in reflectance shortward of about 0.55 $\mu \mathrm{m}$ due to charge transfer absorptions [Tossell et al., 1975; Adams, 1975; Hazen et al., 1977; Burns, 1981] is not considered in detail in our present analysis because the higherenergy (shorter wavelength) wing of this absorption was not measured in any of our spectra. Samples of olivine and orthopyroxene often exhibit narrow absorption features at 1.4 and $1.9 \mu \mathrm{m}$ due to $\mathrm{OH}$ and $\mathrm{H}_{2} \mathrm{O}$ vibrational features in associated weathering products. For pure, unaltered samples, these bands are absent.

The spectral properties of two-component mixtures of olivine and orthopyroxene have not been studied in a detailed and systematic manner. However, Adams [1974], Gaffey and McCord [1979], and Singer [1981] have shown that there are consistent variations in spectral properties with phase abundance. In the present paper, we have undertaken a detailed study of the spectral variations of olivine-orthopyroxene mixtures in order to define the systematics of their spectral behavior and to establish interpretive calibrations. In addition to phase abundance, the effects of phase composition and particle size variations were also considered. An analytical methodology is presented for quantifying the major variables of an olivine-orthopyroxene mixture from a reflectance spectrum.

\section{Procedure}

Seventy-three controlled olivine-orthopyroxene mixtures were prepared to quantify the spectral effects of variations in phase abundance and particle sizes. An additional 12 spectra of olivine-orthopyroxene, olivine-clinopyroxene, and orthopyroxene-clinopyroxene mixtures and their end-members, which formed the basis for an earlier study [Singer, 1981], were used in a qualitative fashion to indicate the effects of clinopyroxene in the spectra but otherwise were not used in our development of calibrations. All spectra were obtained with the spectrogoniometer of the Planetary Geosciences Division at the University of Hawaii with a halon reflectance standard [Singer, 1981]. In all cases, samples were measured at a phase angle of $15^{\circ}$.

Olivine-orthopyroxene mixtures were produced from both dry sieved and wet sieved particle size fractions of the pure end-members. (Mineral samples, when properly wet sieved, tend to exhibit a well-constrained distribution of sizes defined by the sieves through which the sample has passed and/or on which it was retained. Dry sieved samples tend to include a significant fraction of small particles adhering to and coating the large grains. Thus wet sieved samples tend to have better characterized particle size distributions, while dry sieved (or unsieved) tend to more closely approximate regolith textures.)

Purified samples of olivine and orthopyroxene were prepared from two source assemblages by removal of other minerals and by removal of contaminated (e.g., those with inclusions) or altered grains during examination under a binocular microscope. Although absolute purity is not possible, contaminants generally do not exceed $1 \%$ of the sample and, because of the petrographic relationships, do not measurably affect the spectral properties of the material. The two minerals were separately crushed using a hardened steel mortar and pestle, ground in a porcelain mortar, and wet or dry sieved several times. Between sievings, the samples were visually examined and any additional impurities were removed. Any magnetic impurities (e.g., magnetite, shavings from the iron mortar and pestle, etc.) which had escaped removal during visual inspection were magnetically extracted at this point. The wet sieved portions were sieved in methanøl and allowed to dry in a dust-free area.

Appropriate amounts of the purified particle size fractions of the olivine and orthopyroxene end-members were mixed to 


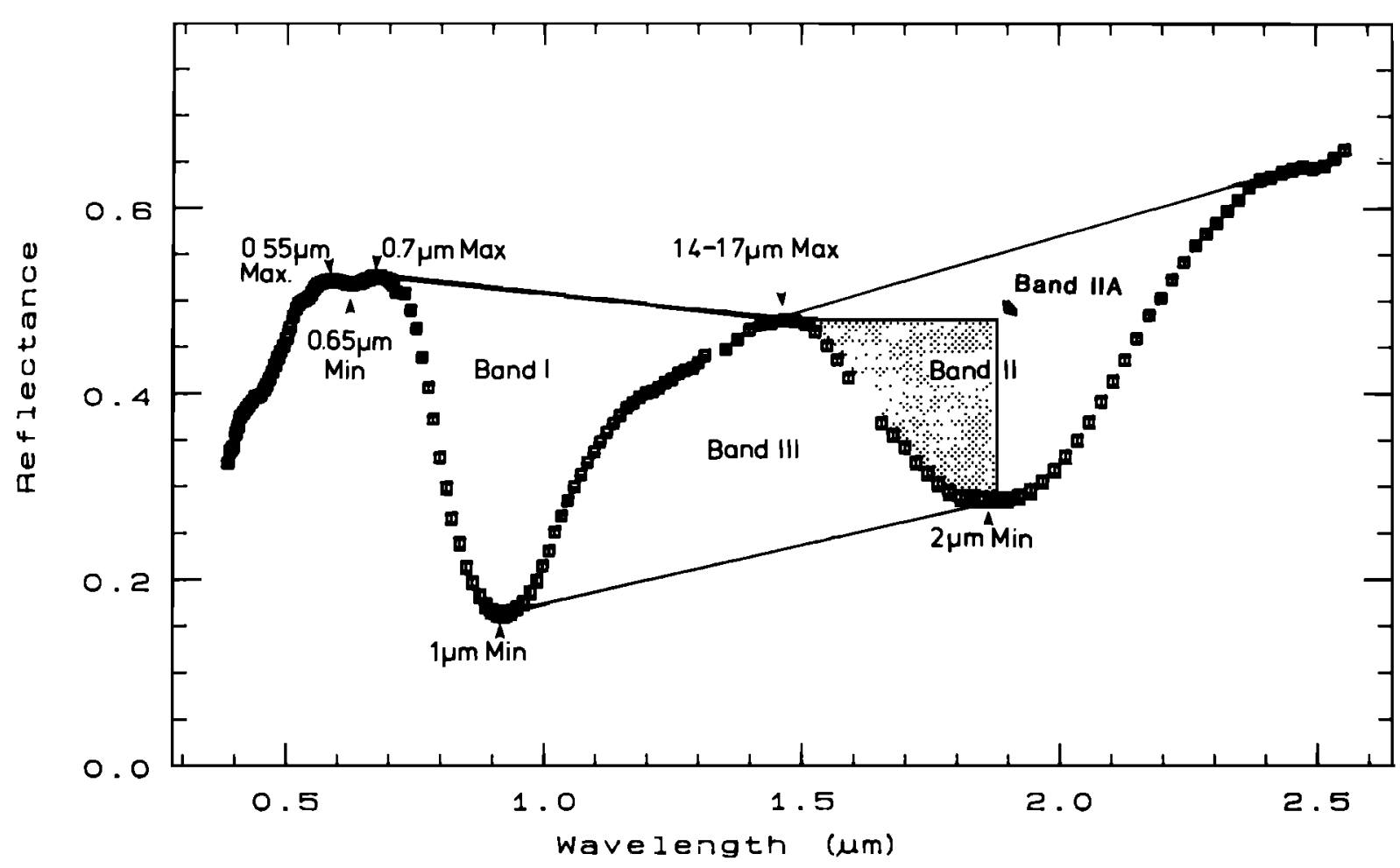

Fig. 1. Typical spectrum of a sample prepared for this study $(65 \%$ olivine, $35 \%$ orthopyroxene; grain size $=38-53 \mu \mathrm{m}$, wet sieved) showing some of the spectral features chosen as being diagnostic or potentially diagnostic. Band IIA is the stippled area in the short-wavelength half of band II. See text and Table 1 for a discussion of the specific criteria for these spectral parameters.

produce the various weight percent fractions and each was placed in a separate container. For the actual spectral measurements, the samples were poured into horizontally oriented sample holders (which were cleaned before each sample) and gently stirred. The holders were tapped to level the sample surface. No compaction or other surface preparation was performed.

The olivine-orthopyroxene mixtures utilized in the present study were prepared predominantly in four particle sizes: 38-53 $\mu \mathrm{m}$, wet sieved; 63-90 $\mu \mathrm{m}$, wet sieved; 63-90 $\mu \mathrm{m}$, dry sieved; and 90-125 $\mu \mathrm{m}$, wet sieved. Mixtures for each of the size suites were prepared at $5 \mathrm{wt} \%$ intervals except for the 63-90 $\mu \mathrm{m}$ wet sieved samples, which were prepared mainly at $10 \%$ intervals. All subsequent references to proportions of end-members refer to weight percent.

The spectral range measured for our samples was $0.38-2.55$ $\mu \mathrm{m}$. The Singer samples were measured over the spectral range $0.65-2.55 \mu \mathrm{m}$. The spectral resolution of the spectrogoniometer is $\sim 1.5 \%$ [Singer, 1981]. This spectral range and resolution are adequate to acquire detailed reflectance spectra of the various mixtures of olivine and orthopyroxene but do not include the complete $2-\mu \mathrm{m}$ band in the clinopyroxene spectrum. The spectra of the clinopyroxene containing mixtures were considered to indicate trends and not to derive a calibration, a task for future work.

\section{SAMPLE Description}

\section{Olivine}

These samples were obtained from unaltered transparent green crystals sorted from a green beach sand beach near South Point on the island of Hawaii. It has a composition of $\mathrm{Fo}_{89}$.

\section{Orthopyroxene}

The orthopyroxene material was obtained from a massive enstatite sample from Bamble, Norway (Ward's Natural Sci- ence Establishment). The source specimen contains a small amount of white fibrous contaminant which was removed during purification process. Its composition is $\mathrm{En}_{\mathbf{8 6}}$ (hypersthene).

\section{Clinopyroxene}

Clinopyroxene-containing mixtures were not measured in this study but are part of the work by Singer [1981], the olivine-clinopyroxene data which were utilized to indicate trends in the present study. The clinopyroxene grains were separated from a granular peridotite found in the core of a volcanic bomb on the upper slopes of Mauna Kea on the island of Hawaii. It is a diopside or diopsidic augite $\left(\mathrm{Wo}_{41} \mathrm{Fs}_{8}\right.$ ).

The chemical analyses of these three minerals were given by Singer [1981].

\section{Special Features Selected for Analysis}

Our analytical approach was basically open-ended. The various olivine-pyroxene spectra were examined to ascertain which, if any, spectral features might be diagnostic for quantifying one or more sample variables such as abundances, chemistries, and physical properties. In this content, "spectral features" could include any parameter of a spectral reflectance or spectral albedo curve such as absorption band center, width, depth, and area; wavelength position, reflectance, or albedo of the maxima, minima, or inflections in the spectral curves; spectral slope or curvature; albedo; or ratios of any of these parameters. Absorption bands were singled out early in the study for detailed examination on the basis of their importance in determining mineral chemistries as previously documented. Three absorption features were identified as being potentially diagnostic. Their locations are approximately 0.65 , 1.0 , and $2.0 \mu \mathrm{m}$. The locations of these and the other spectral features utilized in this study are illustrated in Figure 1.

The spacing of these three absorptions (treating the $1-\mu \mathrm{m}$ 
TABLE 1. Potential Calibrations Investigated

\begin{tabular}{|c|c|}
\hline $\begin{array}{c}\text { Absolute Albedos, } \\
\qquad \mu \mathrm{m}\end{array}$ & $\begin{array}{l}\text { Band Position, } \\
\qquad \mu \mathrm{m}\end{array}$ \\
\hline $\begin{aligned} & 0.55 \text { maximum } \\
& 0.65 \text { minimum } \\
& 0.70 \text { maximum } \\
\sim & 1.0 \text { minimum } \\
\sim & 1.4 \text { maximum } \\
\sim & 1.9 \text { minimum }\end{aligned}$ & $\begin{aligned} & 0.55 \text { maximum } \\
& 0.65 \text { minimum } \\
& 0.70 \text { maximum } \\
\sim & 1.0 \text { minimum } \\
\sim & 1.4 \text { maximum } \\
\sim & 1.9 \text { minimum }\end{aligned}$ \\
\hline Band Areas & Band Area Ratios \\
\hline $\begin{array}{l}\text { Band I } \\
\text { Band II } \\
\text { Band III } \\
\text { Band IA* } \\
\text { Band IIA }\end{array}$ & $\begin{array}{l}\text { band II/band I } \\
\text { band I/band III } \\
\text { band II/band III } \\
\text { band IIA/band IA }\end{array}$ \\
\hline
\end{tabular}

\begin{tabular}{ccl}
\hline \multicolumn{3}{c}{ Relative Reflectance, $\mu \mathrm{m}$} \\
\hline Ratios & Ratios & Ratios \\
\hline $0.7 / 0.55$ & $1.9 / 0.65$ & $1.9 / 0.9$ \\
$0.55 / 0.65$ & $1.4 / 0.7$ & $0.55 / 1.4$ \\
$0.7 / 0.65$ & $0.55 / 0.9$ & $0.55 / 1.9$ \\
$0.9 / 0.65$ & $0.7 / 0.9$ & $0.7 / 1.9$ \\
$1.4 / 0.65$ & $1.4 / 0.9$ & $1.4 / 1.9$ \\
\hline \hline
\end{tabular}

See Figure 1 for examples of spectral parameters.

*Band IA $=$ band I $*[\operatorname{Ref}(0.7 \mu \mathrm{m}) / \operatorname{Ref}(1.4 \mu \mathrm{m})]$.

triplet in the olivine as a single feature) is sufficiently large for the intervening regions to exhibit "peaks" of increased reflectance as the strength of the absorptions decrease with increasing distance from the band centers. These relative maxima were also identified as being potentially diagnostic of certain variables of these assemblages. In order of increasing wavelength they are located at approximately $0.55,0.7$, and $1.4-1.7$ $\mu \mathrm{m}$.

In addition to the three maxima and three minima, five band areas were defined by enclosing portions of the spectral curves (plotted as reflectance versus wavelength) with continua. Straight-line continua were chosen for utilitarian reasons; their geometry and reconstruction is unambiguous. The band $I$ area is defined as the area enclosed by the spectral curve and a straight-line tangent to the relative maxima at 0.7 and $1.4-1.7 \mu \mathrm{m}$, as defined above. The band IA area is the same as band I but multiplied by the $0.7-$ to $1.4-\mu \mathrm{m}$ peak reflectance ratio. The band II area is enclosed by the spectral curve and a straight line fixed on the curve at $2.4 \mu \mathrm{m}$ (because the absorption wing is incomplete) and the 1.4- to $1.7-\mu \mathrm{m}$. maximum. The band IIA area is enclosed by the spectral curve, a straight horizontal line tangent to the $1.4-$ to $1.7-\mu \mathrm{m}$ peak and a vertical line centered at the band II minimum. The band III area is defined by enclosing the spectral curve with a straight-line tangent to the minima at 1.0 and $2.0 \mu \mathrm{m}$. In this case the continuum is the lower boundary of the enclosed region. These band areas are indicated on Figure 1.

The third set of spectral parameters investigated in the present study was the wavelength positions of the various maxima and minima in the spectral reflectance curves. The variation of absorption band position with mineral chemistry has been documented as discussed above. In the present study the shifts in the position of the absorption band minima (as well as other spectral minima or maxima) for olivine-orthopyroxene assemblages were investigated primarily as functions of phase abundance and particle size in mixtures.

\section{Analytical Groupings and General Trends}

As discussed above, four particle size suites of olivineorthopyroxene samples were prepared. In most cases, mixtures of these particle size suites were produced at $5 \mathrm{wt} \%$, intervals from one pure end-member to the other in order to provide a reasonably comprehensive data set in terms of grain size and abundance. All potential calibrations were investigated using end-member abundances as the primary variable. Variations in the behavior of the spectral parameters as a function of phase abundance for the various particle size fractions were compared in order to evaluate the effects of particle size on the potential calibrations. In order to increase the number of potentially useful calibrations and to ameliorate some of the problems of absolute calibrations in remotely sensed data, most of the spectral features were ratioed to one another, resulting in a number of dimensionless parameters.

This analysis produced three general classes of potential calibrations. The largest category of potential calibrations (21) were those involving ratioed or relative spectral parameters. The absolute spectral reflectance parameters (spectral albedos at minima or maxima in the reflectance curve, individual absorption band areas) form a second category (nine). The final group of potential calibrations (six) which were investigated involved the shifts in the wavelength positions of spectral minima and maxima. The specific spectral parameters of each of these 36 potential calibrations are listed in Table 1. Each particular group of calibrations has certain general characteristics as well as particular strengths and weaknesses. The most useful specific calibrations are discussed in detail in the following section, but some generalizations concerning each group are worth describing at this point.

The ratioed or relative spectral parameters have the advantage of being independent of absolute calibrations (e.g., albedo), which in many astronomical situations is difficult to obtain accurately. For the most part, these calibrations were found to be very nearly independent of particle size. Only in a few cases did any particle size fraction (generally the dry sieved 63- to 90- $\mu \mathrm{m}$ suite) deviate from a single trend. In those cases, the complex scattering and absorption conditions resulting from the adhesion of small fragments to the surfaces of larger grains appear to be important. The sensitivity of this group of calibrations to mineral phase abundances is particularly high.

The calibrations involving absolute spectral albedo parameters appear best suited for characterizing grain sizes. In light of the results by Adams and Filice [1967] on albedo variations with changing particle size, this is not surprising. An absolute albedo calibration during the remote-sensing observations would be required in order to apply this class of calibrations.

The third group of calibrations, those involving shifts in the wavelength positions of spectral minima and maxima, complements previous work on these shifts for pure end-members. These calibrations are generally functions of both phase abundance and mineral chemistry but are insensitive to particle size variations.

Table 1 lists the specific spectral parameters which were explored in the present study. Those which are particularly appropriate for determination of one of the assemblage properties are discussed in detail in the next section.

\section{Primary Calibrations}

Almost every parameter investigated in the present study could serve in some way to constrain the properties of an olivine-orthopyroxene assemblage (end-member abundances, 


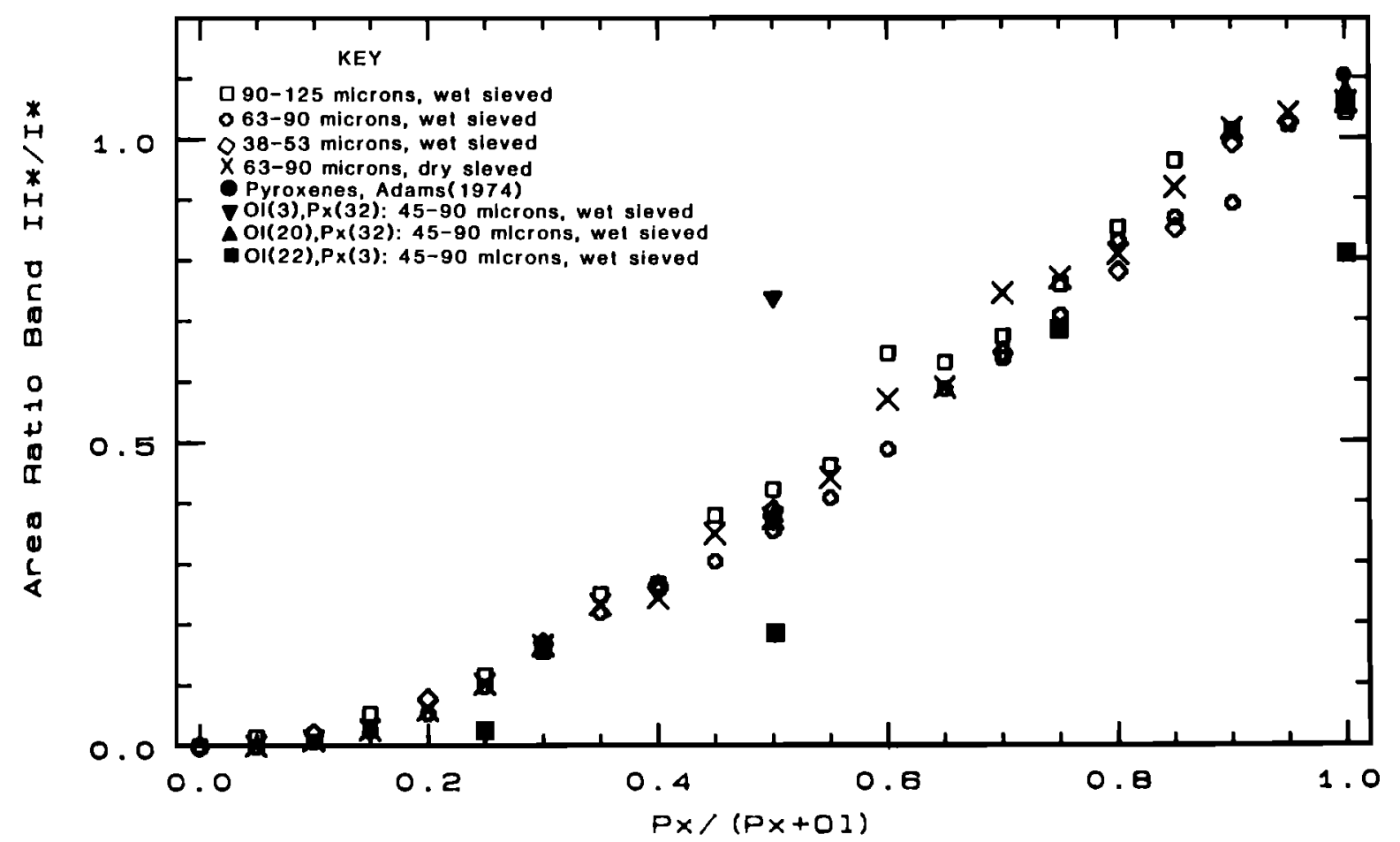

Fig. 2a. A plot of the area ratio band II/band I (see Figure 1) versus orthopyroxene abundance. The symbols correspond to different particle size fractions. No effect of the various particle sizes or textures can be seen in this data. The solid line is a linear least squares fit (slope $=0.024$, intercept $=-0.125$ ) to all the data points between 10 and $90 \%$ pyroxene.

chemistries, and physical properties) from remotely obtained spectral data. However, certain of these spectral calibrations are much more applicable than others in terms of sensitivity to particular assemblage properties, precision of determinations, or applicable range. Only this limited set of the more useful calibrations from the total set investigated is discussed in detail in the present paper. Of the remainder, only those which can be used to verify the results of a primary calibration or which could be applied if one of the primary calibrations produced ambiguous results will be described.

The primary calibrations are presented in groups based on their applicability to the determination of each of the three major variables (phase abundance, phase composition, grain size) of an olivine-orthopyroxene assemblage. While the ideal spectral calibration would be sensitive to only a single property of an assemblage and applicable over the entire range for such assemblages, actual calibrations are generally less than perfect. The problems, limitations, and restrictions are described for each of the calibrations discussed in this section. Insufficient data were available to construct a calibration sequence of similar precision for olivine-clinopyroxene mixtures, but ongoing research should rectify this problem in the near future.

\section{Mineral Phase Abundance Calibrations}

The band area ratios for the 1- and $2-\mu \mathrm{m}$ absorption features as defined by bands I and II versus phase abundance are shown on Figure $2 a$, and those for bands IA and IIA are shown on Figure $2 b$. These two band area ratios (BII/BI and BIIA/BIA) are almost solely functions of phase abundance.

A linear least squares fit to all the BII/BI ratios between 10 and $90 \%$ orthopyroxene provides an excellent match to the data. Only the band area ratios for $0,5,95$, and $100 \%$ pyroxene exhibit any systematic departures from a linear relation- ship. This calibration (Figure $2 a$ ) is applicable over almost the full range of abundance. The estimated uncertainty in the abundance of the orthopyroxene phase determined from this calibration is about $\pm 5 \%$. Although the BII/BI area ratio is applicable only to the olivine-orthopyroxene mixtures, it is apparently insensitive to continuum slope changes introduced by $\mathrm{NiFe}$ metal phases or lunar agglutinates [Adams and McCord, 1970; Farr et al, 1980]. The specific effects of the strong wavelength dependent absorption of phases such as the agglutinate fraction in lunar soils is under investigation by several research groups.

Surface regoliths on airless bodies are subject to comminution by impact, which results in significant shock effects in a fraction of the grains in such a regolith. Adams et al. [1979] and King [1986] have investigated the effect of shock on the reflectance spectra of pyroxenes, olivines, and other mafic assemblages. The BIIA/BIA area ratio (Figure $2 b$ ) is apparently not affected by the spectral effects in shocked pyroxenes. It is, however, more strongly affected by variations in the overall continuum slope of the spectrum.

All four grain size fractions form a narrow linear distribution on Figure $2 a$ (BII/BI). No variation systematically above or below the calibration line could be detected for any of the particle size suites. The dry sieved 63- to $90-\mu \mathrm{m}$ micron sample, with its more complex optical scattering properties where finer grains coat larger particles, shows no systematic deviations from the wet sieved samples. The phase abundance determined from these band area ratios thus appears to be very insensitive to the effects of particle size variations or textural relationships. The distribution of points on Figure $2 b$ (BIIA/BIA) is slightly concave, and exhibits more scatter than those on Figure $2 a$. No significant difference is exhibited by the different size fractions.

The lack of any significant dependence on particle size for 


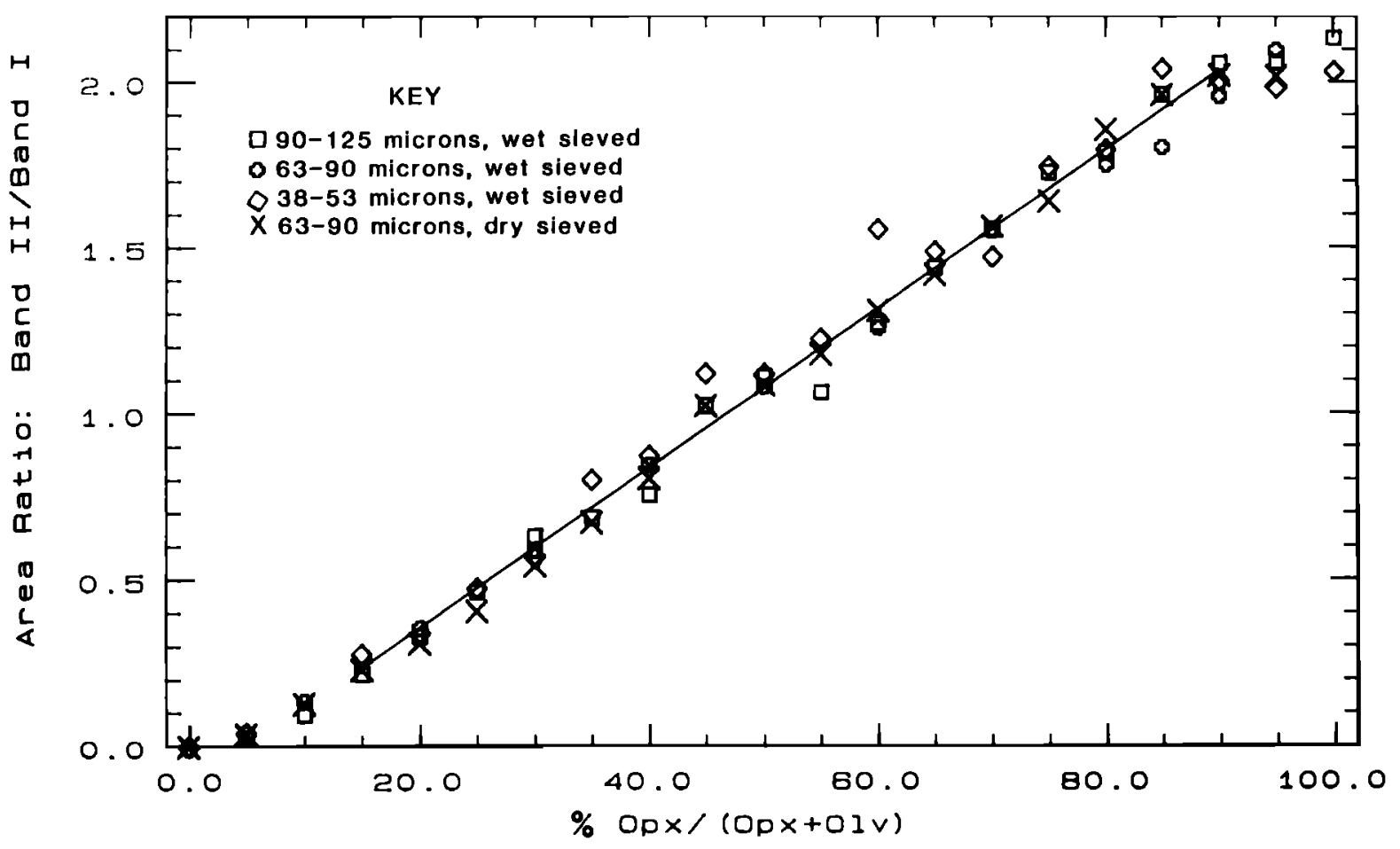

Fig. $2 b$. Same as Figure $2 a$ for band IIA/band IA (see Figure 1) area ratios. Additional points for mixtures of other olivines $\left(\mathrm{Ol}(3)=\mathrm{Fa}_{3}, \mathrm{Ol}(20)=\mathrm{Fa}_{68}, \mathrm{Ol}(22)=\mathrm{Fa}_{39}\right)$ and pyroxenes $\left(\mathrm{Px}(3)=\mathrm{Fs}_{30} \mathrm{Wo}_{1}, \mathrm{Px}(32)=\mathrm{Fs}_{45} \mathrm{Wo}_{3}\right)$. See Cloutis [1985] for additional discussion of these samples.

these calibrations is maintained as long as both the olivine and the pyroxene have similar particle size distributions. A number of lines of evidence suggest that this should be the case in most regoliths. High-pressure compression studies of a number of mafic minerals indicates similar shear strength characteristics for olivine and pyroxene over a range of pressures [Riecker and Seifert, 1964]. Olivine and pyroxene also exhibit similarities in a number of bulk physical properties [Clark, 1966]. It would therefore be expected that each phase in a comminuted assemblage would have generally similar particle size distributions. The sequence of deformational textures in fayalite and augite are similar from both examination of chondritic meteorites and experimental shock tests [Carter et al., 1968]. Grain size and petrographic studies of returned Apollo samples reveals similar particle size distributions for pyroxene and olivine grains in many cases [Kim et al., 1971; McKay et al., 1977]. Experimental comminution of olivine and pyroxene display similar grain size distributions for equivalent impact loadings [Horz et al., 1984].

Olivine and pyroxene phase abundance determinations from the BII/BI and BIIA/BIA area ratio calibrations also appear to be insensitive to changes in end-member chemistry. The band area ratio for pure olivines is essentially zero for all olivine phases, since there are no appreciable $2-\mu \mathrm{m}$ absorption band in the spectrum of most olivines [Burns, 1970b; Hunt and Salisbury, 1970; Adams, 1975; Miyamoto et al., 1981]. Even where very weak absorptions are present in the $2-\mu \mathrm{m}$ region of very iron rich olivines [Adams, 1974; Hunt, 1977], the band $I$ area is so large that the ratio is very nearly zero. A similar insensitivity of the band area ratio to mineral chemistry is present in orthopyroxenes. The area ratios for two other orthopyroxenes (Enstatite $38833\left[\mathrm{Fs}_{12} \mathrm{Wo}_{0}\right]$ and Enstatite EB-175 $\left[\mathrm{Fs}_{23} \mathrm{Wo}_{3}\right]$ [Adams, 1975]) were measured, and they both fell within $10 \%$ of the value obtained for the samples used in the present study. The BIIA/BIA area ratio varies by only $\pm 10 \%$ for all the pyroxene spectra, either measured in the present study or from the literature.

Therefore the end points in either the BII/BI or BIIA/BIA calibrations do not appear to vary as a function of the composition of the olivine or orthopyroxene phases. The linearity of the calibration between the two end points is almost certainly not fortuitous. The olivine and orthopyroxene used in this study are not an equilibrium assemblage, but they have subequal molar iron contents. The linearity of the distribution between the end points needs to be tested with mixtures of olivine and orthopyroxenes with divergent iron contents.

Until those measurements are carried out, there are qualitative arguments which indicate that this linear distribution is generally applicable. Two offsetting processes would be affecting the linearity of the calibration, both a function of chemistry variations: one due to changing band areas and the other due to changing bulk density. To illustrate, consider an assemblage composed of an iron-rich olivine and an iron-poor pyroxene. The band area ratios of the two end-members are constant at about 0.0 and 2.1 , respectively. The increase of the area of band $I$ from the increased abundance of the absorbing species $\left(\mathrm{Fe}^{2+}\right)$ increases the intensity of the olivine absorption feature [Hunt and Salisbury, 1970; Hazen et al., 1977] and results in lower BII/BI and BIIA/BIA area ratios. The intermediate points on the calibration curve would be displaced downward relative to the linear trend by this effect.

However, the more fayalitic olivine has a higher bulk density. Thus fewer olivine particles would be required to provide a given weight percent of the total assemblage. This would tend to mimic a lower total olivine abundance shifting the intermediate points on Figure 2 to the left with respect to the linear trend. The combined effect of these two factors is a net displacement toward the origin, more or less along the linear trend. While quantitative data are not presently available on the relative magnitudes of these two effects, nothing in the 


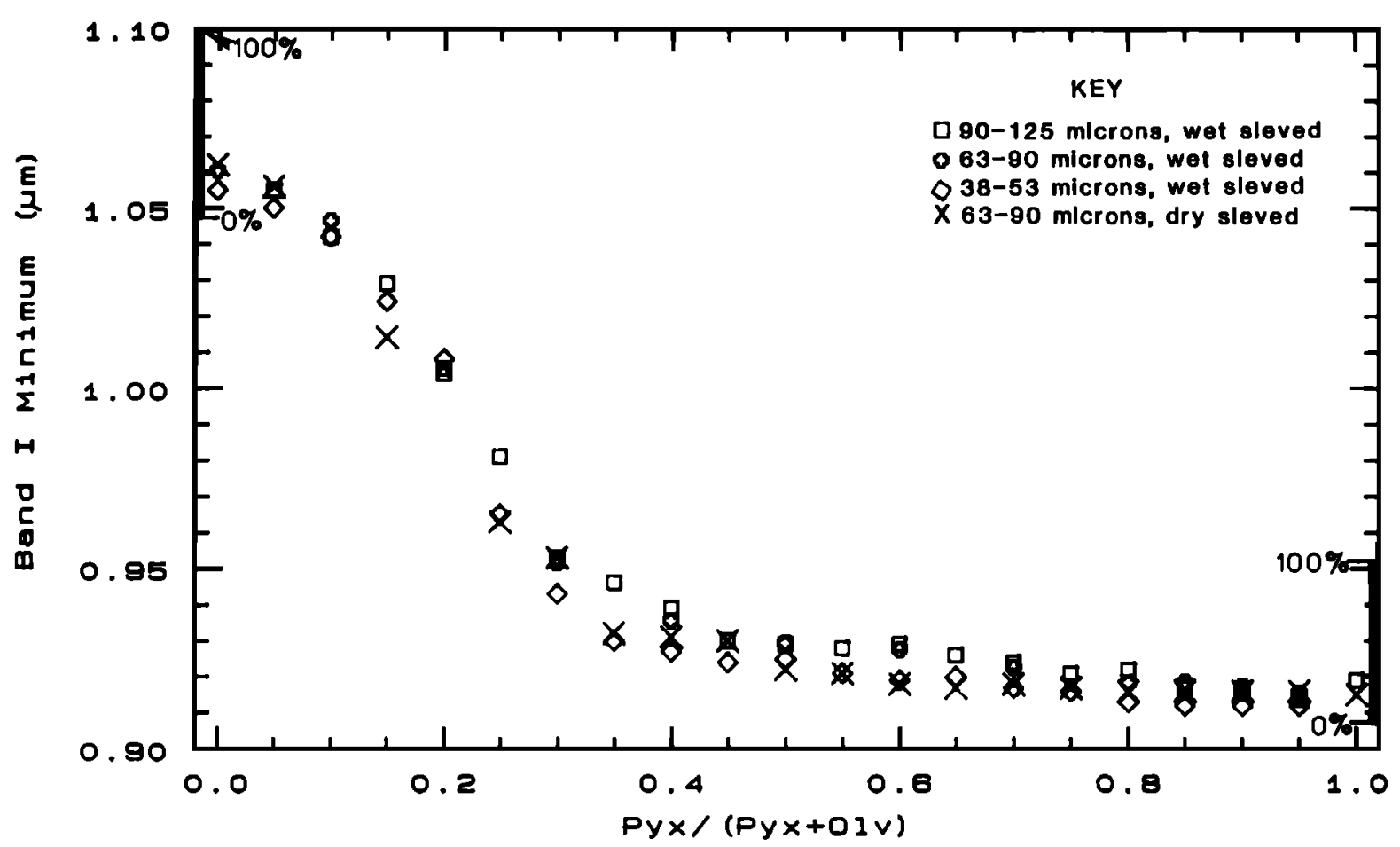

Fig. 3. The variation in the wavelength position of the band I minimum (see Figure 1) as a function of orthopyroxene abundance. The symbols are the same as on Figure $2 a$. The scaled wavelengths range of the band minima for the pure end-members with variation in iron content of the olivines and orthopyroxenes are shown along the left and right vertical scales, respectively. See text for a discussion of the scaling procedure.

present data would indicate that one effect should dominate the other.

The end-member abundances should be resolvable to $\pm 5-10 \%$ from the $\mathrm{BII} / \mathrm{BI}$ area ratio, provided the mineral chemistries and particle sizes of the olivine and orthopyroxene are similar. If a substantial difference in the molar iron content is present between the two phases, then this calibration will underestimate the weight fraction of the more iron-poor phase by an amount proportional to the difference in the iron contents. If a significant difference exists between the mean particle sizes of the two phases in an assemblage, then this calibration will underestimate the weight fraction of the finer phase approximately proportionally to the ratio of the mean particle sizes. The uncertainty in the BIIA/BIA calibration in somewhat larger, but its apparent applicability to Ol-opx-cpx assemblages makes it potentially very useful.

Temperature variations have been found to cause noticeable changes in shapes of mafic mineral spectral curves [Sung et al., 1977; Roush, 1984; Roush and Singer, 1983, 1984, 1986]. Increasing the temperature of an olivine sample results in the shifting of the longer-wavelength wing of the band I absorption toward longer wavelengths. For orthopyroxene the longer-wavelength wings of both major absorption features (1 and $2 \mu \mathrm{m}$ ) shift toward longer wavelengths. The BII/BI area ratio for orthopyroxene at elevated and reduced temperatures varies by less than $10 \%$ from that at room temperature. At the present time there appears to be no reason to introduce a thermal correction into this calibration.

Similar arguments should generally apply to the independence of the BIIA/BIA calibration from changes in phase composition and temperature. However, given the wide variety of iron content in coexisting clinopyroxene phases, its three-component nature ( $\mathrm{Mg}, \mathrm{Ca}$, and $\mathrm{Fe}$ end-members), and the different thermal behavior of the $1-$ and $2-\mu \mathrm{m}$ bands in clinopyroxene spectra, the actual effects of phase composition and temperature are less well constrained. As in the case of the BII/BI calibration, additional work will be required to determine the magnitude of these effects.

The BI/BIII area ratio is similar in nature to the primary calibration in that the ratio increases linearly with increasing pyroxene content. Some deviation of the dry sieved spectra from the rest of the groups is present at the high pyroxene $(>60 \%)$ end of the calibration, somewhat reducing its overall usefulness.

The potential calibrations involving ratios of spectral albedos at pairs of wavelengths (e.g., at a band minimum and at a reflectance maximum) do not appear to be particularly suitable for phase abundance determinations, although several of these parameters are well correlated over limited ranges of phase abundance. Such albedo ratios are sensitive to particle size variations in the bulk assemblage. Variable end-member chemistries also affect albedo ratios, particularly in the olivines [Adams, 1975].

\section{End-Member Mineral Compositions}

As discussed above, the position of the absorption bands in the spectrum of an olivine or pyroxene phase is a function of mineral chemistry. Determination of end-member compositions in mixtures of two or more phases cannot utilize the calibrations developed in that work. In such mixtures for olivine and pyroxene the $1-\mu \mathrm{m}$ absorption band is a compound feature and its position is a function of both mineral phase composition and mineral phase abundance.

The wavelength position of the band I minimum provides a useful calibration of end member chemistries for olivineorthopyroxene assemblages if the end member abundances are known. Figure 3 shows the distribution of band I positions with phase abundance. As long as there are no significant differences between the mean particle size of the two phases, this distribution is not sensitive to the particle size distribution 


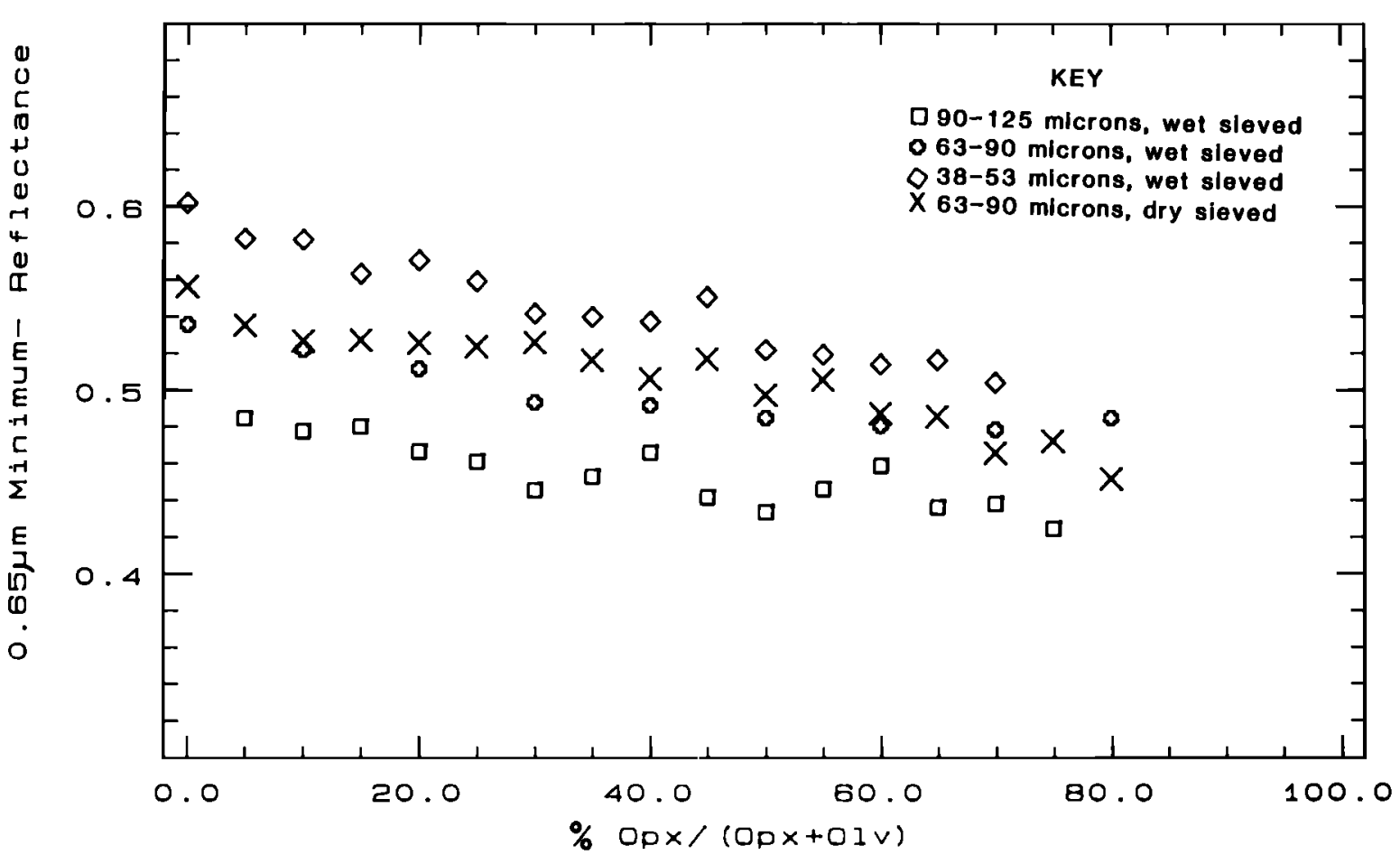

Fig. 4. The albedo of the $0.65-\mu \mathrm{m}$ minimum (see Figure 1) versus phase abundance for the same particle size fractions as in the previous figures. These albedos are only weakly sensitive to end-member abundances for any particular particle size fraction. At an orthopyroxene abundance of $>80 \%$ in our mixtures, the minumum is no longer distinguishable as a discrete feature. The symbols are the same as on Figure $2 a$.

in the assemblages. The wavelength positions of the endmembers correspond to the compositions of the olivine $\left(\mathrm{Fa}_{11}\right)$ and orthopyroxene $\left(\mathrm{Fs}_{14}\right)$ used in this study.

In practice, this calibration is used by first determining the mineral phase abundance. The wavelength positions of the olivine and orthopyroxene band I minima vary approximately linearly as a function of iron content. The calibration curve (Figure 3 ) is adjusted upward or downward so that the observed band minimum position occurs at the determined abundance. The end points (pure olivine and pure pyroxene) then provide the absorption band positions for the pure species which can be interpreted using the calibrations of Adams, Burns, and others.

Conversely, if the end-member chemistries are known, the end points of the calibration curve can be adjusted upwards or downward to the appropriate wavelengths from the mineralogical band calibrations, and the band position can be used as a fairly sensitive indicator of phase abundance at the olivinerich $(>60 \%)$ end of the mixture range. This approach was employed by Gaffey [1984] in the analysis of surface mineralogical variations on the asteroid (8) Flora.

There are several caveats which must be kept in mind. First, one is dealing with a relatively small wavelength shift $(0.14$ $\mu \mathrm{m})$ between the pure end-members. While any spectrometer with the appropriate spectral coverage and resolution should be able to trace out the reflectance curve so that band area ratios can be determined accurately, small but significant wavelength offsets may exist between data obtained by different instruments. Few of the broad spectral coverage instruments utilized in these sorts of mineralogical spectral studies have been calibrated with respect to one another. A careful comparison of the wavelength position of features in the spectra of the same samples measured on the present instrument and in the mid-1970s with the Beckman DK2A spectrometer used by Adams [1974, 1975] and Gaffey [1976] has revealed the presence of a systematic wavelength shift of $0.025 \mu \mathrm{m}$ between these two systems. Since the present instrument employed a wavelength calibration at regular intervals, we choose to view the values obtained here as more accurate and to apply the appropriate correction factor $(+0.025 \mu \mathrm{m})$ to the wavelengths reported by Adams [1974, 1975]. J. B. Adams (personal communication, 1983) notes that a recent wavelength calibration of his instrument indicated a discrepancy of the same sense and magnitude reported here. M. Feierberg (personal communication, 1981) had also noted a discrepancy. This emphasizes the need for cross laboratory calibration standards now that remote-sensing instrumentation is beginning to provide more precise spectral curves where more than gross wavelength positions of features can be determined.

With the wavelength correction factor applied to the spectra of Adams [1974, 1975], the range of values for the band I minima for olivine are from 1.050 to $1.085 \mu \mathrm{m}$ and for orthopyroxene from 0.920 to $0.965 \mu \mathrm{m}$ for the pure magnesium and the pure iron end-members, respectively. It is evident that uncritical use of these scales would yield molar iron contents of about $\mathrm{Fa}_{50}$ for the olivine and about $\mathrm{Fs}_{0}$ for the orthopyroxene. The actual compositions of the two phases are $\mathbf{F a}_{11}$ and $\mathrm{Fs}_{14}$.

The value which is determined for absorption feature position in a reflectance spectrum depends on several factors, including the definition of "position" and the slope of the spectral curve. The lowest point in the absorption feature is termed the band minimum. Various investigators have determined this value in at least three different ways, including (1) by locating the point of lowest reflectance, (2) by fitting some sort of polynomial to the points around the lowest point, or (3) by averaging the wavelengths of a pair of points or several pairs of points on each wing of the feature at some reflectance above that of the band minimum. The first is sensitive to noise in the data, and the last requires that the band be symmetric. 


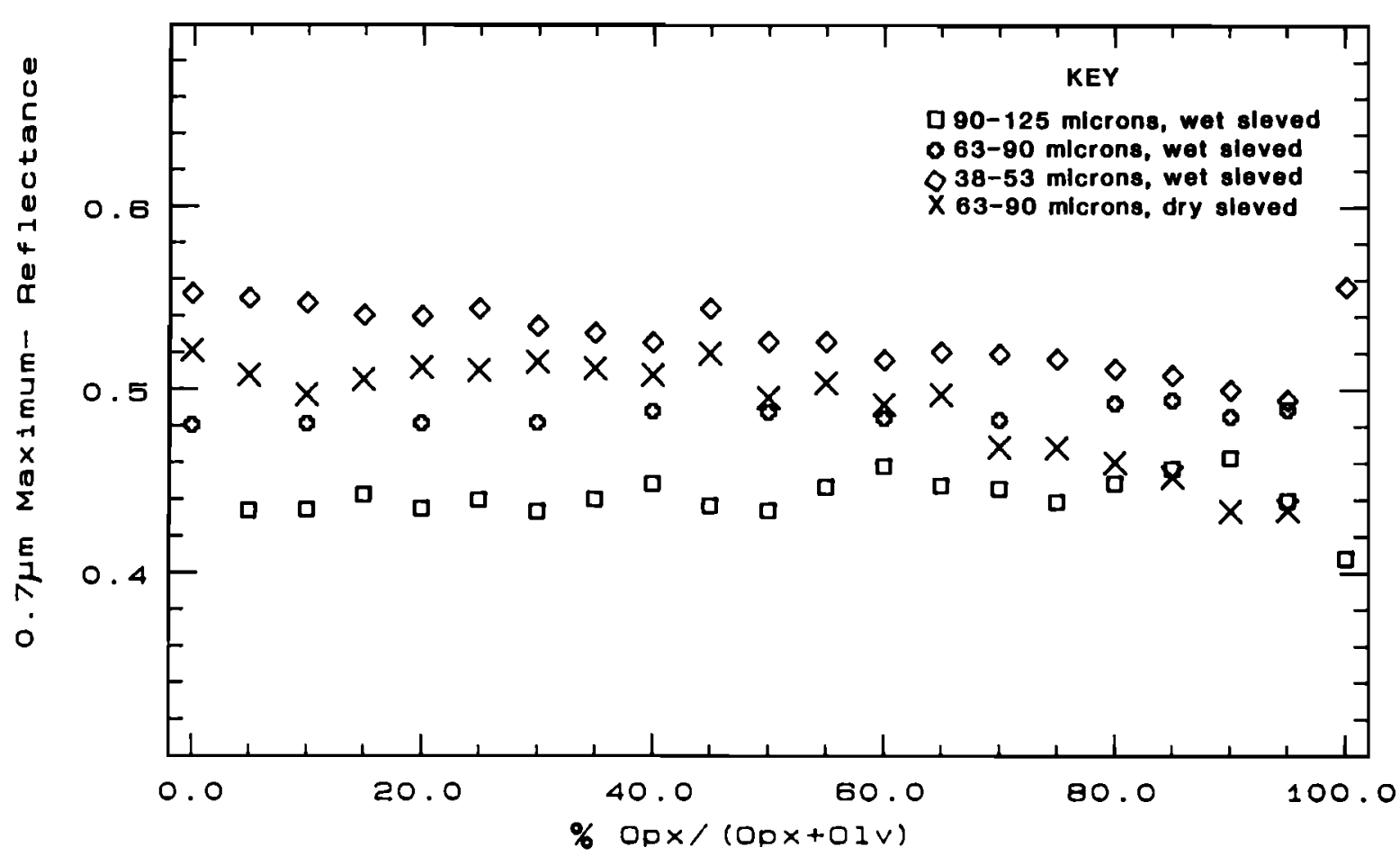

Fig. 5. The albedo of the $0.7-\mu \mathrm{m}$ peak (see Figure 1) versus phase abundance for the same particle size fractions as in the previous figures. This albedo is nearly independent of end-member abundances and remains a distinct feature throughout the entire abundance range. The symbols are the same as on Figure $2 a$.

The polynomial fit approach to the band bottom smoothes out some of the effects of noise in the data and is not affected by overall band shape.

The band center (as opposed to the band minimum) is the wavelength of maximum absorption. If there is no overall continuum slope in the spectrum (e.g., a slope introduced by an additional phase or by another broad absorption feature in the mineral), the band center and the band minimum are coincident. However, if there is a continuum slope in the spectral region of the absorption feature, the band center will be displaced in the downslope direction by an amount related to the slope of the continuum and the shape of the absorption feature.

While the wavelength values given for the absorption band positions of olivine and orthopyroxene depend on the actual parameter being measured, the magnitudes of the shifts in band position with phase chemistry are similar. The wavelength position of the $1-\mu \mathrm{m}$ absorption feature increases by approximately $0.035-0.045 \mu \mathrm{m}$ for both minerals from 0 to $100 \mathrm{~mol} \%$ of the iron end-member, realizing of course that no feature is actually present in the pure magnesium end-member. The linear correlation of the band shift with iron content implies that the correlation curve of Figure 3 can be translated vertically, without requiring a significant geometrical distortion, to accommodate changing iron contents in the endmembers, providing that their iron content is subequal. The molar abundance of the end-members can then be determined from the position of the end points of the calibration in the range of possible molar iron abundances along the vertical axes. For purpose of the present calibration the range of band positions for the end-members are about $1.055 \mu \mathrm{m}\left(\mathrm{Fa}_{0}\right)$ to $1.090 \mu \mathrm{m}\left(\mathrm{Fa}_{100}\right)$ for the left axis (olivine) and $0.911 \mu \mathrm{m}\left(\mathrm{Fs}_{0}\right)$ to $0.956 \mu \mathrm{m}\left(\mathrm{Fs}_{100}\right)$ for the right axis (pyroxene) of Figure 3. These corrected and scaled ranges are plotted along their respective axes on the figure.

The absorption band positions are independent of particle size, providing that the different phases have similar particle size distributions. This calibration is thus a function of both mineral abundance and mineral chemistry and is independent of particle size.

The alternate potential calibrations which were investigated in the present study for determining end-member chemistries are functions of particle size distribution as well as mineral abundance and chemistry. Calibrations involving absolute or relative spectral reflectance features do not appear able to isolate the effects of mineral composition. The change in absolute or relative reflectance due to variation in mineral composition or abundance can often be reproduced by varying the particle size distribution of the mixture.

The set of potential calibrations utilizing wavelength positions of other spectral features as a function of changes in abundance are in general best suited as alternate calibrators. Each of the five remaining potential calibrations of spectral feature position as a function of abundance in this group are limited in some way. The $0.55-\mu \mathrm{m}$ peak and the $0.65-\mu \mathrm{m}$ minimum are not always present as distinct features in all olivines and pyroxenes [Hunt and Salisbury, 1970; Adams, 1974, 1975; Hunt, 1977]. The 0.7- $\mu \mathrm{m}$ peak is present in all but pure forsterite, but the changes in its wavelength position as a function of mineral phase chemistry have not been calibrated. Our data indicate that its wavelength position is independent of particle size. The wavelength position of the 1.4- to $1.7-\mu \mathrm{m}$ peak is independent of particle size and exhibits a large change in its position $(\sim 0.5 \mu \mathrm{m})$ over the range of abundances. The effects of chemistry on its wavelength location are not yet calibrated within the pyroxene group, and it is absent in all but the most fayalitic olivines.

The wavelength position of the $2-\mu \mathrm{m}$ minimum is known to vary with changing $\mathrm{FeO}$ content in orthopyroxenes [Adams, 1974]. Since only the most iron-rich olivines exhibit even a weak absorption band in the $2-\mu \mathrm{m}$ spectral region, the band II position provides a useful calibration of the iron content of 
TABLE 2. Diagnostic Sensitivity and Limitations

\begin{tabular}{lc}
\hline Calibration & Comments \\
\hline $0.55 \mu \mathrm{m}$ maximum & $\begin{array}{c}\text { Absolute Albedo } \\
\text { Not present in high pyroxene mixtures. Good } \\
\text { gran size discrimination for Px } \leq 50 \% . \\
\text { Useful grain size discrimination except at hi } \\
\text { pyroxene contents when minimum is abse }\end{array}$ \\
$0.65 \mu \mathrm{m}$ minimum & $\begin{array}{c}\text { Good grain size discrimination for entire } \\
\text { range of phase abundances. }\end{array}$ \\
$0.70 \mu \mathrm{m}$ maximum & $\begin{array}{c}\text { Not useful for grain size determination. } \\
\text { Useful grain size determination reasonably } \\
\text { good for 20\% } \leq \text { Px } \leq 80 \% .\end{array}$ \\
$\sim 1.4 \mu \mathrm{m}$ maximum mam & $\begin{array}{c}\text { Not useful for grain size determination. } \\
\sim 1.9 \mu \mathrm{m} \text { minimum }\end{array}$
\end{tabular}

$0.55 \mu \mathrm{m}$ maximum

$0.65 \mu \mathrm{m}$ minimum

$0.70 \mu \mathrm{m}$ maximum

$\sim 1.0 \mu \mathrm{m}$ minımum

$\sim 1.4 \mu \mathrm{m}$ maximum

$\sim 1.9 \mu \mathrm{m}$ minımum

Band I

Band II

Band III

Band II/band I

Band III/band II

Band $\mathrm{I} /$ band $\mathrm{III}$

Band IIA/band IA

$0.7 \mu \mathrm{m} / 0.55 \mu \mathrm{m}$

$0.55 \mu \mathrm{m} / 0.65 \mu \mathrm{m}$

$0.7 \mu \mathrm{m} / 0.65 \mu \mathrm{m}$

$0.9 \mu \mathrm{m} / 0.65 \mu \mathrm{m}$

$1.4 \mu \mathrm{m} / 0.65 \mu \mathrm{m}$

$1.9 \mu \mathrm{m} / 0.65 \mu \mathrm{m}$

\section{Band Positions}

Generally moves to longer wavelength with increasing Px. Total shift $\sim 0.03 \mu \mathrm{m}$. Absent in pyroxene-rich assemblages.

Generally moves to shorter wavelength with increasing Px. Total shift $\sim 0.015 \mu \mathrm{m}$. Absent in pyroxene-rich mixtures.

No variation with grain size or abundance.

Sensitive to phase abundance and composition. See text for detailed discussion.

Moves almost linearly to shorter wavelength with increasing Px. Compositional dependence unknown.

Band position unchanged by phase abundance or grain size. Function of pyroxene composition. See text for discussion.

Absolute Band Areas

Good phase abundances for Px $\leq 50 \%$. Fairly independent of grain size. Dry sieved samples systematically lower than wet sieved samples. Requires albedo.

Increases almost linearly with Px abundance. Less grain size dependence than BIII. Dry sieved samples diverge from wet sieved at Px $>50 \%$. Requires albedo.

Increases almost linearly with Px abundance. Some dependence on grain size. Requires albedo.

\section{Band Area Ratios}

Increases linearly with Px abundance. Primary calibration. See text for detailed discussion.

Constant for $P x \geq 25 \%$. Little grain size dependence.

Increases linearly with $\mathbf{P x}$ abundance. Some grain size dependence.

Increases linearly with Px abundance. Primary calibration. See text for discussion.

\section{Reflectance Ratios}

Increases slightly $(\sim 10 \%)$ with increasing Px abundance. Single distribution for all particle sizes and sievings.

Very slight decrease with increasing pyroxene abundance. No grain size dispersion.

Nearly constant. No grain size dispersion. May vary with phase composition.

Small initial rise to $\mathrm{Px} \sim 20 \%$, then slight decrease to $\mathrm{Px}=80 \%$. Considerable grain size dispersion at low Px abundance, decreasing grain size dispersion with increasing Px. Dry sieved samples systematically higher than wet sieved.

Initially decreases with increasing Px abundance but becomes nearly constant. Dry sieved sample is systematically higher than wet sieved. Useful for phase abundance of olivine rich mixtures.

Decreases with increasing Px abundance. No systematic grain size dispersion in wet sieved samples. Dry sieved samples fall systematically above trend of wet sieved.
TABLE 2. (continued)

\begin{tabular}{|c|c|}
\hline Calibration & Comments \\
\hline $1.4 \mu \mathrm{m} / 0.7 \mu \mathrm{m}$ & $\begin{array}{l}\text { Decreases to Px } \sim 50 \% \text {, then increases with } \\
\text { increasing Px abundance. Wet sieved sam- } \\
\text { ples show no particle size dispersion. Dry } \\
\text { sieved samples systematically higher than } \\
\text { wet sieved. Not too useful unless it varies } \\
\text { with phase composition. }\end{array}$ \\
\hline $0.55 \mu \mathrm{m} / 0.9 \mu \mathrm{m}$ & $\begin{array}{l}\text { Decreases then increases with increasing Px } \\
\text { abundance. Some grain size dispersion. Wet } \\
\text { sieved samples systematically lower than } \\
\text { dry sieved. }\end{array}$ \\
\hline $0.7 \mu \mathrm{m} / 0.9 \mu \mathrm{m}$ & $\begin{array}{l}\text { Increases with increasing Px abundance. Some } \\
\text { particle size dispersion. Dry sieved samples } \\
\text { are systematically lower, and their distri- } \\
\text { bution has a lower slope than the wet sieved } \\
\text { samples. }\end{array}$ \\
\hline $1.4 \mu \mathrm{m} / 0.9 \mu \mathrm{m}$ & $\begin{array}{l}\text { Ratio decreases to } P x \sim 25 \% \text { then increases } \\
\text { with increasing Px abundance. Dry sieved } \\
\text { samples are systematically lower than wet } \\
\text { sieved. Not too useful unless it varies with } \\
\text { phase composition. }\end{array}$ \\
\hline $1.9 \mu \mathrm{m} / 0.9 \mu \mathrm{m}$ & $\begin{array}{l}\text { Significant decrease from } \mathrm{Px}=0 \% \text { to } \sim 20 \% \\
\text { with large grain size dispersion. Ratio } \\
\text { nearly constant for } \mathrm{Px}>\mathbf{3 0} \% \text {. Dry sieved } \\
\text { samples systematically lower than wet } \\
\text { sieved. }\end{array}$ \\
\hline $0.55 \mu \mathrm{m} / 1.4 \mu \mathrm{m}$ & $\begin{array}{l}\text { Increases but becomes constant beyond } \\
\text { Px }=30 \% \text {. No systematic grain size disper- } \\
\text { sion in wet sieved samples. Dry sieved sam- } \\
\text { ples systematically lower then wet sieved. }\end{array}$ \\
\hline $0.55 \mu \mathrm{m} / 1.9 \mu \mathrm{m}$ & $\begin{array}{l}\text { Increases with Px abundance. No grain size } \\
\text { dispersion among wet sieved samples. Dry } \\
\text { sieved samples systematically lower than } \\
\text { wet sieved. }\end{array}$ \\
\hline $0.7 \mu \mathrm{m} / 1.9 \mu \mathrm{m}$ & $\begin{array}{l}\text { Increases with Px abundance. No systematic } \\
\text { grain size dispersion for Px } \leq 80 \% \text {. Dry } \\
\text { sieved samples systematically lower than } \\
\text { wet sieved. }\end{array}$ \\
\hline $1.4 \mu \mathrm{m} / 1.9 \mu \mathrm{m}$ & $\begin{array}{l}\text { Increases with Px abundance. No systematic } \\
\text { grain size dispersion for Px } \leq 80 \% \text {. Dry } \\
\text { sieved samples follow trend with lower } \\
\text { slope than wet sieved samples. }\end{array}$ \\
\hline
\end{tabular}

orthopyroxenes in olivine-orthoproxene mixtures. This calibration for orthopyroxene chemistry in olivine-orthopyroxene mixtures is independent of phase abundance and of particle size but has a number of limitations and uncertainties at present.

The shape (and apparent band position) of the $2-\mu \mathrm{m}$ spectral region in observational data can be modified substantially by the added flux (strongly increasing with wavelength) of the thermal emission of a warm surface. Although in principle, this thermal component can be subtracted from the observed spectrum, an accurate correction is not a trivial exercise [e.g., Clark, 1979]. Moreover, the long-wavelength wing of the 2- $\mu \mathrm{m}$ orthopyroxene band shifts toward longer wavelength with increasing temperature [Roush, 1984], which introduces an additional needed correction factor. Fortunately, the surface temperatures on earth and in the asteroid belt are low enough to minimize both effects.

\section{Particle Size Calibrations}

Present work indicates that the most difficult property of an olivine-orthopyroxene assemblage to determine accurately from spectral data is the particle size distribution. Absolute reflectance values of various minima and maxima appear best suited as calibrations for this purpose.

The albedos at the $0.65-\mu \mathrm{m}$ spectral minimum and the 
TABLE 3. Spectrally Determined Phase Abundances

\begin{tabular}{ccc}
\hline $\begin{array}{c}\text { BII/BI Area } \\
\text { Ratio }\end{array}$ & $\begin{array}{c}\text { Interpreted } \\
{[01: \text { Px }]}\end{array}$ & $\begin{array}{c}\text { Published } \\
{[01: \text { Px }]}\end{array}$ \\
\hline 1.455 & $34: 66$ & $25: 75$ \\
0.923 & $56: 44$ & $50: 50$ \\
0.429 & $77: 23$ & $75: 25$ \\
\hline
\end{tabular}

*Singer [1981].

$0.7-\mu \mathrm{m}$ spectral peak (Figures 4 and 5 , respectively) are relatively independent of end-member abundance but are dependent on phase chemistry. Preliminary results show that the albedo of these features decreases linearly with increasing iron content and that the magnitude of the albedo decrease is similar for both olivine [Adams, 1975] and orthopyroxene [Hunt and Salisbury, 1970]. The curves representing the albedo of the $0.65-\mu \mathrm{m}$ minimum (Figure 4) and the $0.7-\mu \mathrm{m}$ maximum (Figure 5) for the different particle size sets can be vertically translated up or down according to the $\mathrm{FeO}$ content of the end members. No geometric manipulations of the calibration data should be required given the similarity in the magnitude of the change in reflectance with equal changes in the chemistry for both minerals. The differences in albedo for the various grain sizes are sufficiently large so that a general particle size determination can be made. Thus with the abundance and chemistry determinable from the previously mentioned calibrations, the particle size distribution can be determined for olivine-orthopyroxene mixtures from spectral data. However, since surface texture as well as particle size plays an important role in albedo, this calibration must be viewed as indicative but not as definitive.

Absolute spectral albedos are difficult to obtain with accuracy in many remote sensing situations. The task may be further hampered by the presence of spectrally neutral opaque phases, whose effects are to suppress the albedo independent of particle size. If the absolute spectral albedo of an olivineorthopyroxene assemblage (free of contaminants) can be determined, it is possible to constrain particle size.

The remaining potential calibrations involving absolute reflectances are not as generally applicable. The $0.55-\mu \mathrm{m}$ peak data are only discernible over a limited range of phase abundances. The albedo of the $1-\mu \mathrm{m}$ minimum as a function of abundance allows resolution of grain sizes, but the changes in reflectance as a function of chemistry appear to be different and nonlinear for the two end-members. The 1.4- to $1.7-\mu \mathrm{m}$ and $2.0-\mu \mathrm{m}$ features are not present in the majority of olivines so the interaction of albedo and chemistry cannot be ascertained for the very olivine-rich assemblages.

Other potential calibrations can discriminate between different particle sizes only over a limited range of assemblage properties. The reflectance ratios at $0.55 \mu \mathrm{m} / 1.0 \mu \mathrm{m}, 1.0$ $\mu \mathrm{m} / 0.65 \mu \mathrm{m}, 1.4 \mu \mathrm{m} / 1.0 \mu \mathrm{m}$, and $2.0 \mu \mathrm{m} / 1.0 \mu \mathrm{m}$ versus abundances discriminate particle sizes for mixtures with lower olivine abundances $(<45 \%)$. Their behavior for different endmember chemistries is uncertain at this time. The absence of these features in certain phase abundance ranges also limits their utility.

Table 2 summarizes the diagnostic sensitivity and limitations of the 33 spectral and albedo properties investigated.

\section{Applying the Analytical Procedure:} AN EXAMPLE

In order to illustrate the systematic approach to the analysis of the reflectance spectrum of an olivine-orthopyroxene mix- ture, three of the spectra measured by Singer [1981] were treated as unknowns.

After establishing that the spectra are predominantly olivine-orthopyroxene mixtures by absorption band criteria, the first step in the analysis was to determine the end-member abundances. The band I and band II areas were measured using a planimeter and the resulting values were ratioed. The band area ratios, the derived phase abundances, and the stated phase abundances [Singer, 1981] are listed in Table 3.

With the end-member abundances established, the composition of the mineral phases was then determined. A cubic polynomial was fit to the 10 spectral channels on either side of the band I minimum for the 34:66 mixture and solved to give the wavelength position of the minimum. The value for this spectrum was $0.917 \mu \mathrm{m}$. With the end-member abundances already determined, a point on the graph of Figure 3 is fixed. For the calibration curve to intersect this point, the curve must be translated slightly downward. The magnitude of the vertical translation of the calibration curve was $\sim 0.003 \mu \mathrm{m}$. The positions of the end points of the translated calibration curve then fall at $1.052 \mu \mathrm{m}$ and $0.914 \mu \mathrm{m}$, corresponding to $\mathrm{Fa}_{6 \pm 7}$ and $\mathrm{Fs}_{7 \pm 5}$, respectively.

Once the end-member abundances and compositions had been determined, the third parameter, particle size, could be estimated. For the 34:66 spectrum, the $0.65-\mu \mathrm{m}$ albedo versus abundance curve (Figure 4) was used to make a particle size determination. The vertical scale on Figure 4 was shifted downward (or the points upward) by about $7 \%$ to reflect the interpreted lower iron content in these silicates (relative to that of the mafic assemblage used in the calibration). The reflectance of the $0.65-\mu \mathrm{m}$ maximum for the test spectrum was 0.48 . When plotted against its end-member abundances (34:66), this point fell between the points for the 90-125 and 63-90 $\mu \mathrm{m}$ particle size fractions (wet sieved) and near the 63-90 $\mu \mathrm{m}$ (dry sieved) fractions. A particle size near or somewhat below $90 \mu \mathrm{m}$ would be indicated.

Singer [1981] describes the samples as mixtures of wet sieved, 45-90 $\mu \mathrm{m}$ olivine $\left(\mathrm{Fa}_{11}\right)$ and orthopyroxene $\left(\mathrm{Fs}_{14}\right)$ in the proportions listed in Table 3 . The agreement of the spectrally derived determinations with the given values is within the combined uncertainties of the spectral abundance calibration $( \pm 5-10 \%)$ and of the stated abundance values ( \pm 5-10\%).

The spectrally derived phase abundances appear to underestimate systematically the pyroxene phase. An examination of Figure 1 of Singer [1981] shows narrow, well-defined "water" bands near 1.4 and $1.9 \mu \mathrm{m}$ in his orthopyroxene spectrum. These represent the spectral contribution of the fibrous, hydrated silicate mineral which is present as an accessory phase in the massive Bamble "orthopyroxene" specimens. The spectra indicate that orthopyroxene samples used in his mixtures were contaminated with significant amounts of this amphibole phase.

This fibrous phase is most probably a member of the anthrophyllite-cummingtonite subgroup of the asbestoform amphiboles, which occur in the Bamble formation. Such amphiboles generally exhibit reasonably strong transition metal features near $1 \mu \mathrm{m}$ but not not exhibit significant bands in the $2 \mu \mathrm{m}$ spectral region. The presence of a significant amphibole component would increase the absorbance in band I but not in band II. It would thus mimic an increased olivine content. The Singer [1981] mixtures are thus (at least) threecomponent systems. This would account for the systematically 
low pyroxene abundances determined from the spectral calibration.

\section{SUMmary AND CONCLUSIONS}

An analytical approach is outlined which permits the interpretation of visible and near-IR spectral reflectance data to determine the mineralogic and petrologic parameters of olivine-orthopyroxene mixtures, including end-member abundances, chemistries, and particle size.

The ratio of two band areas (band I [ $\sim 1 \mu \mathrm{m}]$, band II [ $\sim 2$ $\mu \mathrm{m}]$ ) is a nearly linear function of end-member abundances with sufficient resolution and insensitivity to chemistry and grain size that abundances can be determined with useful accuracy. The band I minimum is sensitive to both mineral abundance and chemistry. With known abundances of the end-members, band I position can be utilized to determine their chemistries. Particle sizes can be determined from the absolute reflectance at $0.65 \mu \mathrm{m}$ if the abundances and endmember chemistries are known. While certain aspects of the method are not as precise as would be desired, the basic approach provides a powerful additional remote sensing capability for certain classes of mafic assemblages.

Several issues must be addressed in order to enhance the applicability of this type of interpretive methodology to more varied mafic assemblages. Some of these issues include (1) the effects of spectrally neutral opaque materials on an olivinepyroxene spectrum and how to compensate for their influence, (2) the development of an interpretive procedure for the spectra of olivine-clinopyroxene mixtures, and (3) the development of similar analytical system for three-component mixtures of olivine, orthopyroxene, and clinopyroxene.

Acknowledgments. The authors to express their gratitude to Pamela Blake, Ted Roush, Jonathon Gradie, Michael Garcia, and Joanne Sinton for their valuable support and assistance during this research effort. We also wish to thank John Adams and Carle Pieters for their reviews which helped to improve the manuscript. Various portions of this work were supported at the University of Hawaii by NASA grant NSG-7312 and by a Sigma Xi Foundation grant to E.A.C. and at Rensselaer Polytechnic Institute by NASA grant NAGW-642. Planetary Geosciences Division, Hawaii Institute of Geophysics, University of Hawaii, publication 470 .

\section{REFERENCES}

Adams, J. B., Visible and near-infrared diffuse reflectance spectra of pyroxenes as applied to remote sensing of solid objects in the solar system, J. Geophys. Res., 79, 4829-4836, 1974.

Adams, J. B., Interpretation of visible and near-infrared diffuse reflectance spectra of pyroxenes and other rock-forming minerals, in Infrared and Raman Spectroscopy of Lunar and Terrestrial Minerals, edited by C. Karr, pp. 91-116, Academic, Orlando, Fla., 1975.

Adams, J. B., and A. L. Filice, Spectral reflectance 0.4 to 2.0 microns of silicate rock powders, J. Geophys. Res., 72, 5705-5715, 1967.

Adams, J. B., and T. B. McCord, Remote sensing of lunar soil mineralogy: Implications from visible and near-infrared reflectivity of Apollo 11 samples, Proc. Apollo 11 Sci. Conf., 1937-1945, 1970.

Adams, J. B., and T. B. McCord, Electronic spectra of pyroxenes and interpretation of telescopic spectral reflectivity curves of the moon, Proc. Lunar Sci. Conf., 3rd, 3021-3034, 1972.

Adams, J. B., F. Horz, and R. V. Gibbons, Effects of shock-loading on the reflectance spectra of plagioclase, pyroxene, and glass, Lunar Planet. Sci., X, 1-3, 1979.

Bancroft, G. M., R. G. Burns, and R. A. Howie, Determination of the cation distribution in the orthopyroxene series by the Mossbauer effect, Nature, 213, 1221-1223, 1967.

Burns, R. G., Crystal field spectra and evidence of cation ordering in olivine minerals, Am. Mineral., 55, 1608-1632, $1970 a$.

Burns, R. G., Mineralogical Applications of Crystal Field Theory, Cambridge University Press, New York, $1970 \mathrm{~b}$.
Burns, R. G., Intervalence transitions in mixed-valence minerals of iron and titanium, Annu. Rev. Earth Planet. Sci., 9, 345-383, 1981.

Burns, R. G., R. M. Abu-Eid, and F. E. Huggins, Crystal field spectra of lunar pyroxenes, Proc. Lunar Sci. Conf., 3rd, 533-543, 1972.

Burns, R. G., D. J. Vaughan, R. M. Abu-Eid, M. Witner, and A. Morawski, Spectral evidence for $\mathrm{Cr}^{3+}, \mathrm{Ti}^{3+}, \mathrm{Fe}^{2+}$ rather than $\mathrm{Cr}^{2+}$ and $\mathrm{Fe}^{3+}$ in lunar ferromagnesium silicates, Proc. Lunar Sci. Conf., 4th, 983-994, 1973.

Carter, N. L., C. B. Raleigh, and P. S. DeCarli, Deformation of olivine in stony meteorites, J. Geophys. Res., 73, 5439-5461, 1968.

Clark, R. N., Planetary reflectance measurements in the region of planetary thermal emission, Icarus, 40, 94-103, 1979.

Clark, S. P., Jr., Handbook of Physical Constants, Mem. Geol. Soc. Am., 97, 587 pp., 1966.

Clayton, D. D., Supernovae and the origin of the solar system, Space Sci. Rev., 24, 147-226, 1979.

Cloutis, E. A., Interpretive techniques for reflectance system of mafic minerals, M.S. thesis, Univ. of Hawaii, Honolulu, 1985.

Farr, T. G., B. A. Bates, R. L. Ralph, and J. B. Adams, Effects of overlapping optical absorption bands of pyroxene and glass on the reflectance spectra of lunar soils, Proc. Lunar Planet. Sci. Conf., 1lth, 719-729, 1980.

Gaffey, M. J., Spectral reflectance characteristics of the meteorite classes, J. Geophys. Res., 81, 905-920, 1976.

Gaffey, M. J., Rotational spectral variations of asteroid (8) Flora: Implications for the nature of the S-type asteroids and for the parent bodies of the ordinary chondrites, Icarus, 60, 83-114, 1984.

Gaffey, M. J., and T. B. McCord, Mineralogical and petrological characterizations of asteroid surface materials, in Asteroids, edited by T. Gehrels, pp. 688-723, University of Arizona Press, Tucson, 1979.

Hazen, R. M., H. K. Mao, and P. M. Bell, Effects of compositional variation on absorption spectra of lunar olivines, Proc. Lunar Sci. Conf., 8th, 1081-1090, 1977.

Hazen, R. M., P. M. Bell., and H. K. Mao, Effects of compositional variation on absorption spectra of lunar pyroxenes, Proc. Lunar Planet. Sci. Conf., 9th, 2919-2934, 1978.

Horz, F., M. J. Cintala, T. H. See, F. Cardenas, and T. D. Thompson, Grain size evolution and fractionation trends in an experimental regolith, Proc. Lunar Planet. Sci. Conf., 15th, Part 1, J. Geophys. Res., 89, suppl., C183-C196, 1984.

Hunt, G. R., Spectral signatures of particulate minerals in the visible and near infrared, Geophysics, 42, 501-513, 1977.

Hunt, G. R., and J. W. Salisbury, Visible and near-infrared spectra of minerals and rocks, I, Silicate minerals, Mod. Geol., 1, 283-300, 1970.

Johnson, P. E., M. O. Smith, S. Taylor-George, and J. B. Adams, A semiempirical method for analysis of the reflectance spectra of binary mineral mixtures, J. Geophys. Res., 88, 3557-3561, 1983.

Johnson, P. E., M. O. Smith, and J. B. Adams, Quantitative analysis of planetary reflectance spectra with principle components analysis, Proc. Lunar Planet. Sci. Conf., 15th, Part 2, J. Geophys. Res., 90, suppl., C805-C810, 1985.

Kım, Y. K., S. M. Lee, J. H. Yang, J. H. Kim, and C. K. Kim, Mineralogical and chemical studies of lunar fines 10084,148 and 12070,98, Proc. Lunar Sci. Conf., 2nd, 747-753, 1971.

King, T. V. V., Contributions toward a quantitative understanding of reflectance spectroscopy: Phyllosilicates, olivine and shocked materials, Ph.D. thesis, Univ. of Hawaii, Honolulu, 1986.

Lewis, J. S., Chemistry of the planets, Annu. Rev. Phys. Chem., 24, 339-351, 1973.

Mao, H. K., and P. M. Bell, Interpretation of the pressure effect on the optical absorption bands of natural fayalite to $20 \mathrm{~kb}$, Year Book Carnegie Inst. Washington, 71, 524-527, 1972.

McKay, D. S., M. A. Dungan, R. V. Morris, and R. M. Fruland, Grain size, petrographic, and FMR studies of the double core 60009/10: A study of soil evolution, Proc. Lunar Sci. Conf., 8th, 2929-2952, 1977.

Miyamoto, M., A. Mito, Y. Takano, and N. Fujii, Spectral reflectance $(0.25-2.5 \mu \mathrm{m})$ of powdered olivines and meteorites, and their bearing on surface materials of asteroids, Mem. Natl. Inst. Polar Res. Spec. Iss. Jen., 20, 345-361, 1981.

Riecker, R. E., and K. E. Seifert, Shear deformation of upper mantle mineral analogs: Tests to 50 kilobars at $27^{\circ} \mathrm{C}, J$. Geophys. Res., 60 , 3901-3911, 1964.

Rossman, G. R., Optical absorption spectra of major minerals in Luna 24 sample 24170 , papers presented to the Conference on Luna 24, Lunar Sci. Inst., Houston, Tex., 1977. 
Roush, T. L., Effects of temperature on remotely sensed mafic mineral absorption features, M.S. thesis, 129 pp., Unıv. of Hawan, Honolulu, 1984.

Roush, T. L., and R. B. Singer, The effect of thermal variations on reflectance spectra of mafic minerals, Lunar Planet. Sci., XIV, 654 $655,1983$.

Roush, T. L., and R. B. Singer, Gaussian analysis of $1 \mu \mathrm{m} \mathrm{Fe}^{2+}$ absorptions of mafic minerals, Lunar Planet. Sci., XV, 695-696, 1984.

Roush, T. L., and R. B. Singer, Gaussian analysis of temperature effects on the reflectance spectra of mafic minerals in the $1-\mu \mathrm{m}$ region, J. Geophys. Res., 91, 10,301-10,309, 1986.

Runciman, W. A., D. Sengupta, and J. T. Gourley, The polarized spectra of iron in silicates, II, Olivine, Am. Mineral., 58, 451-456, $1973 a$.

Runciman, W. A., D. Sengupta, and M. Marshall, The polarized spectra of iron in silicates, I, Enstatite, Am. Mineral., 58, 444 450, $1973 b$.

Singer, R. B., Near-infrared spectral reflectance of mineral mixtures: Systematic combinations of pyroxenes, olivine and iron oxides, $J$. Geophys. Res., 86, 7967-7982, 1981.
Sung, C.-M., R. B. Singer, K. M. Parkin, R. G. Burns, and M. Osborne, Temperature dependence of $\mathrm{Fe}^{2+}$ crystal field spectra: Implications to mineralogical mapping of planetary surfaces, Proc. Lunar Sci. Conf., 8th, 1063-1079, 1977.

Tossell, J. A., D. J. Vaughan, and K. H. Johnson, The electronic structure of rutile, wustite, and hematite from molecular orbital calculations, Am. Mineral., 59, 319-334, 1974.

E. A. Cloutis, Department of Geology, University of Alberta, Edmonton, Alberta, Canada T6G 2E3.

M. J. Gaffey, Department of Geology, West Hall, Rensseler Polytechnic Institute, Troy, NY 12181.

T. L. Jackowski, 4139 Kensington Street, Concord, CA 94521.

K. L. Reed, 1531 Makiki Street \# 306, Honolulu, HI 96822.

(Received November 12, 1985;

revised June 20, 1986;

accepted June 24,1986 .) 